\title{
Historia
}

\section{Reorganización documental del Centro Histórico Cultural de la Enfermería Iberoamericana: relato de experiencia}

\author{
Documentary reorganization of the Cultural and \\ Historical Center of Ibero-American Nursing: report \\ of experience
}

Reorganização documental do Centro Histórico Cultural da Enfermagem Ibero-Americana: relato de experiência

Genival Fernandes de Freitas ${ }^{1}$, Taka Oguisso ${ }^{2}$, Magali Hiromi

Takashi ${ }^{3}$, Thais Araújo Silva ${ }^{4}$, Bárbara Barrionuevo Bonini ${ }^{5}$

${ }^{1}$ PhD. Departamento de Orientação Profissional (ENO) (São Paulo). Correo electrónico: genivalf@usp.br

${ }^{2}$ PhD Departamento de Orientação Profissional (ENO) (São Paulo). Correo electrónico:

takaoguisso@uol.com.br

3 Programa de Pós-Graduação em Gerenciamento em Enfermagem (PPGEn), Escola de Enfermagem da USP, São Paulo, Brasil.Correo electrónico: magalitakashi@usp.br

${ }_{4}^{4}$ Programa de Pós-Graduação em Gerenciamento em Enfermagem (PPGEn), Escola de Enfermagem da USP, São Paulo, Brasil Correo electrónico: taarsi2@hotmail.com

5PhD Departamento de Orientação Profissional (ENO) (São Paulo). Correo electrónico: bonini@usp.br

Cómo citar este artículo en edición digital: Freitas, G.F., Oguisso, T., Takashi, M.H., Silva, T.A. E

Bonini, B.B. (2019). Reorganización documental del Centro Histórico Cultural de la Enfermería

Iberoamericana: relato de experiencia. Cultura de los Cuidados (Edición digital), 23(53). Recuperado de http://dx.doi.org/10.14198/cuid.2019.53.07

Correspondencia: Thais Araújo Silva. Escola de Enfermagem da USP. Av. Dr. Enéas de Carvalho Aguiar, 419. Sala 112. CEP: 05403-000. São Paulo-SP

Correo electrónico de contacto: taarsi2@hotmail.com / bonini@usp.br Recibido: 12/11/2018; Aceptado: 18/01/2019

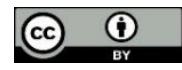

\section{ABSTRACT}

Objective: To report the joint experience of reorganizing materials from the collection of the Cultural Historical Center of the IberoAmerican Nursing of the School of Nursing of the University of São Paulo, carried out from 2013 to 2015.

Method: The partnerships and restructuring and reorganization strategies of the project were listed in the period between 2013 and 2015, which covered three stages to achieve it and the collections that 
integrate this center were listed.

Results: It was noted that the reopening of the new Center, in an accessible and better distributed space, increased the number of site visits, which today is a mandatory stop in activities of some undergraduate and postgraduate courses of the Institution, as well as in the activities that seek to expose what is and what does the nursing profession, as is the case of the event "USP and the professions", promoted by the ProRectory of Culture and Extension.

Conclusions: This "new" Center has achieved its goal of not being a static and lifeless museum, but of being a place of reconstruction of the identity and history of a profession, often mystified.

Keywords: Teaching, nursing, history of nursing, culture and extension.

\section{RESUMO}

Objetivo: Relatar a experiência conjunta de reorganizar os materiais do acervo do Centro Histórico Cultural da Enfermagem Ibero Americana da Escola de Enfermagem da Universidade de São Paulo, realizado no período de 2013 a 2015.

Método: Foram elencadas as parcerias e as estratégias de reestruturação e reorganização do projeto, no período entre 2013 e 2015, que percorreu três etapas para sua consecução e foram listados os acervos que integram.

Resultados: Notou-se que a reinauguração do novo Centro, em um espaço acessível e melhor distribuído, aumentou o número de visitas ao local, que hoje é parada obrigatória em atividades de algumas disciplinas de graduação e pós-graduação da Instituição, bem como nas atividades que buscam expor o que é e o que faz a enfermagem, como é o caso do evento "USP e as profissões", promovido pela PróReitoria de Cultura e Extensão.
Conclusões: Este "novo" Centro conseguiu alcançar seu objetivo, de não ser um museu estático e sem vida, mas de ser um local de reconstrução da identidade e da história de uma profissão, por muitas vezes, mistificada.

Palavras chave: Ensino, enfermagem, história da enfermagem, cultura e extensão.

\section{RESUMEN}

Objetivo: Relatar la experiencia conjunta del proceso reorganizador de los materiales del acervo del Centro Histórico Cultural de la Enfermería Iberoamericana de la Escuela de Enfermería de la Universidad de São Paulo, realizado en el período de 2013 a 2015.

Método: Se establecieron las asociaciones $\mathrm{y}$ las estrategias de reestructuración y reorganización del proyecto, en el período entre 2013 y 2015, que recorrió tres etapas para su consecución y se enumeraron los acervos que integran este centro.

Resultados: Se notó que la reinauguración del nuevo Centro, en un espacio accesible y mejor distribuido, aumentó el número de visitas al local, que hoy es parada obligatoria en actividades de algunas disciplinas de graduación y postgrado de la Institución, así como en las actividades que buscan exponer lo que es y lo que hace la enfermería, como es el caso del evento "USP y las profesiones", promovido por la Pro-Rectoría de Cultura y Extensión.

Conclusiones: Este "nuevo" Centro logró alcanzar su objetivo, de no ser un museo estático y sin vida, sino de ser un lugar de reconstrucción de la identidad y de la historia de una profesión, muchas veces, mistificada.

Palabras clave: Enseñanza, enfermería, historia de la enfermería, cultura y extensión. 


\section{INTRODUÇÃO}

No dia 20 de outubro de 1992 foi inaugurado, na Escola de Enfermagem da Universidade de São Paulo (EEUSP), o Centro Histórico da Enfermagem IberoAmericana (CHCEIA), difundido por um grupo de docentes vinculados ao Departamento de Enfermagem Materno Infantil e Psiquiátrica, da referida Escola, composto pelas professoras Ilza Marlene Kuae Fukuda, Margareth Angelo e Hideko Takeushi Forcella (Oguisso, 2000). Na época de sua criação, o centro tinha como enfoque compartilhar, intercambiar e se integrar aos objetivos comuns com as instituições congêneres, principalmente da América Latina, de Portugal e da Espanha (Conjunto dos países Ibero-Americanos) (Campos et al., 2008). O CHCEIA nasceu com o objetivo de recuperar a História da Enfermagem, como um local dinâmico que não apenas armazenasse itens históricos, mas que pudesse ajudar na divulgação e desmistificação da Enfermagem, tanto para pessoas leigas quanto para os ingressantes no curso e na profissão da Enfermagem (Cianciarullo, 1992).

Cabe ressaltar que no ato de sua constituição, o CHCEIA tinha como objetivos: apoiar e desenvolver pesquisas envolvendo as temáticas da história e legislação da enfermagem, cultura dos cuidados e biografias; recolher, armazenar e preservar obras literárias, artísticas, objetos e documentos; apoiar e desenvolver atividades educativas relativas à história da enfermagem, assim como ações que visassem dar visibilidade sobre os significados e abrangências das práticas da enfermagem; contribuir para o estabelecimento de uma política cultural vinculada à recuperação da memória histórica da enfermagem, por meio da preservação de acervos documentais, tecnologias e materiais de importância histórica, incluindo recursos imagéticos; promover exposições fixas e itinerantes de grande, médio e pequeno porte, simultâneas ou não, sobre materiais desse acervo; estimular a participação de alunos de graduação e pós-graduação, docentes e funcionários da EEUSP no sentido de ampliar o reconhecimento da constituição histórica da enfermagem como profissão. A ideia inicial do Centro Histórico se pautava na concepção de que o patrimônio tem significado político, o que o leva a ser essencial numa construção de identidade nacional (Maia, 2012).

Infelizmente, com o passar do tempo, o Museu (como ficou conhecido) deixou de cumprir o seu papel como centro de ensino e pesquisa, e por 20 anos ocorreu aquilo que se temia, um repositório de artigos antigos que não tinham ligação com o ensino e pesquisa da enfermagem exercida na referida Escola ou fora dela. O CHCEIA, que se encontrava no último andar da EEUSP, um andar de difícil acesso, especialmente para pessoas com dificuldade de mobilidade, tornou-se um corredor para a sala de aula, por onde passavam alunos que não tinham qualquer motivação ou explicação sobre os artefatos que ali estavam armazenados. Havia muitos documentos esparsos e mal armazenados e que precisavam ser submetidos a um rigoroso processo de higienização, classificação e organização antes que pudessem ser disponibilizados de forma correta e segura para consulta. Dessa forma, buscou-se, no ano de 2013, apoio da Pró-Reitoria de Cultura e Extensão Universitária da Universidade de São Paulo e da Fundação de Amparo à Pesquisa do Estado de São Paulo (FAPESP), para a reorganização do Centro Histórico.

Com o apoio destes parceiros foram 
captados recursos para a reforma do espaço físico, reorganização e armazenamento de seu acervo. Os recursos disponibilizados permitiram a mudança para o primeiro andar do prédio da Biblioteca "Wanda de Aguiar Horta", da EEUSP, tornando o acesso mais fácil para os visitantes, permitindo, também que o mesmo fosse acessado por pessoas com dificuldade de mobilidade. Essa reorganização envolveu não somente a coordenação do Centro, mas também a direção da Escola de Enfermagem e diversos alunos de doutorado, mestrado e graduação. Como fruto desse trabalho, o "novo" CHCEIA foi reinaugurado em 6 de novembro de 2015, com a presença de autoridades, como a Profa. Maria Arminda do Nascimento Arruda, Pró-reitora de Cultura e Extensão da USP e a Profa. Maria Amélia de Campos Oliveira (atual Diretora da EEUSP) e as Professoras Tamara Iwanow Cianciarullo, Diná Monteiro da Cruz, Maria Luiza Riesco Bellini, Taka Oguisso, Anna Maria Chiesa e Dayse Risatto Tronchin, além de outros professores da Escola, funcionários técnicos e administrativos, alunos de graduação, pós-graduação, residentes, enfermeiros de instituições parceiras no ensino da EEUSP. Dessa forma, esse artigo tem como objetivo relatar a experiência conjunta de reorganizar os materiais do acervo do Centro Histórico Cultural da Enfermagem Ibero Americana da Escola de Enfermagem da Universidade de São Paulo, realizado no período de 2013 a 2015, para que pudessem ser disponibilizados para a comunidade como fonte de ensino, pesquisa, cultura e extensão.

\section{MATERIAIS E MÉTODOS}

Para que a reestruturação e reorganização do acervo do Centro Histórico acontecessem, percorreu-se três etapas para sua consecução: a primeira consistiu na proposição, em 2013, à Pró-Reitoria de Cultura e Extensão Universitária da Universidade de São Paulo de um projeto de inovação, a fim de preservar acervos documentais, memórias e monumentos. Para tanto, elaborou-se um projeto que buscava não apenas reorganizar os materiais arquivados no CHCEIA, mas que também contemplasse a busca de um novo espaço para a reorganização da exposição permanente (Freitas et al., 2016).

A segunda etapa envolveu a participação voluntária de alunos de pós-graduação no trabalho de seleção, classificação, higienização e digitalização da massa documental. Essa etapa durou pouco mais de dois anos. Os alunos voluntários participaram de workshops promovidos pelo Serviço de Arquivo da Universidade de São Paulo (SAUSP) para que pudessem manusear, higienizar, classificar e digitalizar de maneira segura todos os itens (Freitas et al., 2016). No total, participaram dessa etapa 1 aluno de doutorado, 3 alunos de mestrado, 2 alunos de graduação que foram contemplados com bolsa da Pró-Reitoria de Cultura e Extensão Universitária da USP (PRCEU) e 2 funcionários técnicos administrativos.

A terceira etapa consistiu na "guarda segura" dos documentos físicos, tratados e digitalizados segundo as normas técnicas do SAUSP, garantindo, inclusive, controles de temperatura e umidade do local da guarda (Freitas et al., 2016).

\section{RESULTADOS E DISCUSSÃO \\ Propósitos atuais do CHCEIA da EEUSP}

O Centro Histórico Cultural da Enfermagem levou a complementação 
Ibero-Americana para fazer jus ao intercâmbio de experiências e troca de conhecimentos de docentes da EEUSP para o desenvolvimento de projetos em outros países, especialmente da América Latina. Por exemplo, logo na entrada do CHCEIA há uma placa em tributo à parceria estabelecida entre a EEUSP e o Instituto Superior de Enfermagem da Universidade Agostinho Neto, em Angola. Trata-se de um reconhecimento à Escola de Enfermagem da USP por favorecer o desenvolvimento da Enfermagem naquele país africano.

Os acervos documentais do CHCEIA, que englobam documentos escritos, imagéticos, jornalísticos, dentre outros, estão organizados e classificados de forma a facilitar o acesso e a consulta do público interessado em conhecê-los. Alguns desses acervos encontram-se totalmente digitalizados.

Todo esse trabalho foi realizado em parceria com muitas pessoas, como afirmou o Prof. Dr. Genival Fernandes de Freitas (Conselho Regional de Enfermagem, 2015, p. 41):

Nosso sonho foi alcançado. O trabalho envolveu pesquisadores, professores e servidores, técnicos e administrativos da própria Universidade. Houve a participação de várias cabeças pensando o modus operandi, como se fosse um verdadeiro laboratório a fim de aprimorar esse espaço da construção do saber.

De acordo com o regimento de sua constituição, os objetivos contemporâneos do novo Centro englobam o apoio e desenvolvimento de pesquisas em níveis de graduação e pós-graduação, envolvendo as temáticas da história e legislação da enfermagem, cultura dos cuidados e biografias; recolhimento, armazenamento e preservação de obras literárias, artísticas, objetos e documentos que constituam a história da enfermagem em nível nacional ou internacional; apoio e desenvolvimento de atividades educativas relativas à história da enfermagem no ensino de graduação e pós-graduação, além de ações que visem dar visibilidade sobre os significados e abrangências das práticas da enfermagem (o que o enfermeiro faz); contribuição para o estabelecimento de uma política cultural vinculada à recuperação da memória histórica da enfermagem, por meio da preservação de acervos documentais, tecnologias e materiais de importância histórica, incluindo recursos imagéticos; promoção de exposições fixas e itinerantes de grande, médio e pequeno porte, simultâneas ou não, sobre materiais desse acervo; estímulo à participação de alunos de graduação e pós-graduação, docentes e funcionários da EEUSP no sentido de ampliar o reconhecimento da constituição histórica da enfermagem como profissão.

Dessa forma, a reorganização estimula não apenas o uso do CHCEIA para o ensino e pesquisa, mas também permite a promoção de atividades de cultura e extensão para toda a comunidade.

\section{Acervos do CHCEIA da EEUSP Acervo Fotográfico}

Existem centenas de fotografias disponíveis no Centro. Todas tratadas, selecionadas, classificadas e organizadas por décadas, com descrição pormenorizada, inseridas em planilha e já digitalizadas na integralidade. Hoje é possível acessar estas fontes de forma eletrônica. Mas, vale lembrar que as fontes imagéticas primárias estão disponíveis também no Núcleo de Documentação e Memória (NUDOM), que é parte do CHCEIA.

Cabe pontuar que a digitalização das fotografias foi um processo importante para 
que futuramente as mesmas possam ser consultadas, sem a necessidade de manipulação por conta da preservação do material. Para Luchesi et al., (2006, p. 568), "há sempre resistências a esta restrição, mas é preciso ter em perspectiva que o homem é um dos maiores agressores dos objetos de caráter histórico".

\section{Acervo jornalístico}

Encontram-se categorizados e higienizados jornais de diferentes décadas que fazem alusão ao trabalho da enfermeira e à criação da EEUSP.

Este acervo invoca a memória jornalística sobre o que é enfermagem em diversos contextos e épocas. São fontes riquíssimas para a pesquisa em níveis de graduação e pós-graduação. Assim como as fotografias, as matérias jornalísticas encontram-se tratadas e digitalizadas, com descrições pormenorizadas de cada fonte para facilitar a consulta. Fontes para estudo, utilizando-se matérias jornalísticas imbricadas à História, são imprescindíveis para dar valor ao cenário estudado, tanto coletivamente quanto individualmente (Bergamo, 2011). Estas fontes permitem ao pesquisador e alunos compreender as representações sociais da profissão em diferentes épocas da sua trajetória.

Vale salientar que essas representações são primordiais para a construção da identidade de uma profissão.

\section{Acervo documental}

Todo acervo é documental, pois engloba os vestígios de um passado; entretanto, há um espaço no NUDOM onde são armazenados e enviados todos os documentos de valor histórico incomensurável, como relatórios das primeiras líderes da enfermagem brasileira, mormente da direção da Escola, a exemplo dos relatórios da direção da Profa. Edith de Magalhães Fraenkel que foi a organizadora e 1..$^{\text {a }}$ diretora da EEUSP, diplomada pela Escola de Enfermagem da Philadelphia General Hospital (EUA) em 1925 e influenciou, em 1926, a criação da Associação Nacional de Enfermeiras Diplomadas Brasileiras que hoje é conhecida como Associação Brasileira de Enfermagem (ABEn). Sua competência possibilitou à EEUSP se comparar aos altos padrões de qualidade internacional de ensino (Carvalho, 1980).

Existem também, outros documentos peculiares como cartas, ofícios, telegramas, etc; muitos deles são reveladores da força política da Escola de Enfermagem da USP na reconfiguração da identidade profissional no Brasil.

Esse acervo possui vestígios de grandes acontecimentos na enfermagem brasileira, como, por exemplo, a organização do I Congresso Nacional de Enfermagem, em 1947, por essa Escola (Carvalho, 1976).

Outro exemplo importante é a introdução do ensino da Enfermagem Psiquiátrica, por Ella Hasenjaeger (consultora americana que trabalhou nessa Escola à época da Dona Edith Fraenkel), deixando seu legado à tessitura de uma área de saber, de práticas e de uma identidade profissional, plasmandose como coletivo, com suas entidades, agremiações e coletividades (Oguisso, Freitas, Takashi, 2013).

Os diversos documentos presentes no CHCEIA possuem grande valor histórico e são fontes para pesquisas no campo da história, possibilitando a análise de tais documentos como interpretações das representações de cada época.

Corroborando esta afirmativa Barros (2013, p. 135), relata que:

A historiografia, ao superar o positivismo ingênuo do século XIX, foi tendendo a valorizar cada vez mais esta dimensão da 
fonte histórica textual como "discurso". Hoje, poderíamos dizer que a maior parte das práticas historiográficas insere-se em uma História do Discurso. Um discurso qualquer pode ser analisado tanto a partir de uma "abordagem qualitativa" como a partir de uma 'abordagem quantitativa', ou de uma 'abordagem serial' que examina documentos reunidos em série.

Pontua-se que esse espaço dispõe de um local próprio e adequado para preservação documental, com controle de temperatura e umidade.

\section{Acervo dos Objetos da Assistência de Enfermagem e em Saúde}

Estão expostos no novo espaço do Centro Histórico centenas de objetos utilizados por enfermeiros em diferentes épocas da trajetória histórica da profissão.

Segundo Oguisso (2016), desde 1942, a Diretora da EEUSP Edith Fraenkel, em parceria com as demais enfermeiras contratadas, elaborava técnicas e procedimentos de enfermagem que seriam ensinados mais tarde tanto no Hospital das Clínicas, quanto na Escola.

As novas gerações de enfermeiros ou as gerações de futuros enfermeiros podem vislumbrar o que e como era fazer acontecer o cuidado, quais eram as tecnologias utilizadas no cuidado do ser humano, alargando as concepções do próprio cuidado. Seringas de vidro, agulhas metálicas reutilizáveis e limadores das mesmas, materiais para uso cirúrgico da época, são alguns exemplos dos artigos que compõem esse acervo.

\section{Acervo das obras históricas da enfermagem brasileira e internacional}

No acervo do CHCEIA encontram-se obras históricas da enfermagem, tanto de origem brasileira, como oriundos de âmbito estrangeiro ou internacional.
O conjunto de obras raras em idiomas como: português, inglês, espanhol e japonês permitem aos visitantes e estudantes contemplarem o saber da enfermagem em diferentes contextos.

Dentre as obras catalogadas, encontra-se a versão em inglês do primeiro "Levantamento de Recursos Humanos e Necessidades de Enfermagem", realizado por Beatrice Lenington, logo depois de completado o Levantamento (1958) e editada pela Fundação Rockfeller.

Essa pesquisa de dois anos de duração, financiada pela Fundação Rockefeller, foi um esforço para mapear o perfil da enfermagem brasileira à época, podendo, a partir dela, sustentar políticas para a ampliação da atuação e do contingente de enfermagem no país (Secaf, Sanna, 2003).

Outra obra de grande valor que está disponibilizada no acervo é o livro "Notas sobre Enfermagem", traduzido por Amália Corrêa de Carvalho, em 1989, do original "Notes on Nursing", de autoria de Florence Nightingale, escrito em 1859 (Oguisso, 2016).

Em relação às obras de internacionalização da EEUSP, destaca-se a atuação da Profa. Dra. Taka Oguisso que ocupou os cargos de Enfermeira Consultora e Diretora Executiva Adjunta do Conselho Internacional de Enfermeiras (ICN, na sigla em inglês), em Genebra-Suíça, no período 1987 a 1997. Há distintivos, placas de homenagem, entre outros.

Para ser contratada no ICN havia a exigência de indicar nomes das pessoas que eram chefes da Taka. Assim, foram indicados Amália Corrêa de Carvalho (chefe do Departamento de Orientação Profissional-ENO), Dra. Yoriko Kamiyama (diretora da EEUSP), no Hospital Brigadeiro seu chefe era Dr. Mario da Costa Galvão Filho (diretor desse hospital), na ABEn 
nacional (membro do ICN na época) a presidente era Maria Ivete Ribeiro de Oliveira e a presidente anterior havia sido Dra. Circe de Melo Ribeiro, que também se prontificou, voluntariamente, a fazer a recomendação. Todos eles responderam ao ICN enviando as cartas em inglês para Constance Holleran. Dr. Galvão fez em francês, idioma oficial de Genebra. Taka somente tomou conhecimento da existência dessas cartas em 1992 quando se tornou Diretora Executiva Adjunta, o que lhe dava acesso ao arquivo de documentos confidenciais.

\section{Acervo das Indumentárias}

Definitivamente o acervo que contempla réplicas das roupas utilizadas por enfermeiras e alunas em diferentes épocas é o principal sucesso do CHCEIA. O acervo possui réplicas de roupas utilizadas não apenas na EEUSP e conta ainda com alguns itens doados por ex-alunos.

As roupas e indumentárias que se encontram no CHCEIA apontam algumas características da enfermagem brasileira que valorizavam a conduta e a rigidez de normas tão presentes na enfermagem. Sobre isso, Gastaldo e Meyer (1989) descrevem que um dos legados de Florence para a enfermagem foi a prevalência da conduta e da moral, muitas vezes em detrimento do conhecimento científico, o que trouxe para a profissão certa dificuldade para analisar criticamente a realidade na qual viviam e um atraso na busca por seus direitos e deveres.

Este acervo também dispõe de uniforme militar de enfermeiras e alunas da Escola de Enfermagem da Cruz Vermelha Brasileira, (lembrando que a Cruz Vermelha, tem como lema "na paz e na guerra, caridade", dada sua origem ligada à guerra e serviço militar); e também uniforme de estágios práticos das alunas da EEUSP nas décadas de 1940/50, até os dias mais atuais. Neste contexto, destaca-se a importância da Cruz Vermelha na formação do enfermeiro, pois de acordo com Porto, Campos e Oguisso (2009), entre 1916 a 1930 existia uma grande valorização no mercado por enfermeiras que se formavam nessa escola.

Refletir, por exemplo, quanto ao uso de uniforme para a representação da profissão de Enfermagem, é imprescindível para caracterizar a identidade da enfermeira em diferentes épocas. Sob esse aspecto, Mecone (2014, p. 216) retrata bem a questão acima ao citar a representação do uniforme das Enfermeiras da Cruz Vermelha Brasileira (CVB) durante a época varguista:

No caso das enfermeiras da CVB, elas se enxergavam através de suas vestes, tamanha era a representação sob sua identidade profissional e a expressão de seus uniformes. Sabe-se que a norma imposta aos militares nos serviços sempre foi em torno da disciplina -e com a enfermagem não era diferente, tanto na formação como no exercício profissional.

Pontua-se que a temática no tocante à (re)configuração da identidade do(a) enfermeiro(a) vem sendo discutida por diversos autores, na tentativa de buscar uma imagem que possa corresponder aos anseios da profissão, tais como: Silva, 2015; Bellaguarda et al., 2011; Padilha, Nelson, Borestein, 2011.

\section{Acervo dos objetos institucionais $e$ biográficos}

Este acervo é composto de lembranças de professoras desta Escola, da ABEn, dos Conselhos de fiscalização do exercício da enfermagem e, também, de entidades internacionais, como o Conselho Internacional de Enfermeiras (CIE).

Ele conta ainda com objetos pessoais de 
docentes, como os da Prof. ${ }^{a}$ Dra.Wanda de Aguiar Horta; além de objetos de arte, quadros, entre outros.

\section{Acervo de Oralidade}

Composto por cerca de 80 entrevistas com antigas professoras, líderes nacionais e internacionais da enfermagem, dentro e fora da USP; este acervo integra o projeto "Memória da Enfermagem brasileira e em São Paulo".

Ele dispõe de depoimentos gravados, transcritos e digitalizados de enfermeiros(as) de diversas regiões do país, e que atuaram em entidades representativas de classe, ou em outros campos profissionais. Com ele busca-se dar visibilidade ao que era e ao que se busca ou se vislumbra para o futuro da enfermagem.

A cada ano esse acervo tem aumentado, graças à parceria de alunos de pósgraduação dos diversos programas da USP e de outras Universidades que cursam ou cursaram a disciplina "Análise histórica da enfermagem", sob a coordenação inicial da Profa. Dra. Taka Oguisso e, atualmente, do Professor Dr. Genival Fernandes de Freitas.

A rememoração de eventos, episódios, ocorrências, opiniões, dentre outros, por meio da oralidade, permite transcender a tradução da escrita, pois revelam comunicações verbais e não verbais entoadas de sentimentos para o fato relatado. Sendo assim, a "evanescência da oralidade dá lugar ao espaço visual da escrita" (Galvão, 2006, p. 418).

\section{Acervo da Residência das alunas da Escola de Enfermagem da USP}

Esse acervo aponta para a disposição do mobiliário do quarto das alunas (com cama, guarda roupa, prateleiras para livros, escrivaninha, cadeira, pia, espelho), à época do internato, além de alguns objetos da copa, refeitório, cozinha e escritório.
Cabe pontuar que, o internato para as alunas era obrigatório, até mesmo para as que residiam em São Paulo. Inicialmente, antes de terminada a construção do edifício da Escola, as alunas ocupavam o 6..$^{\circ}$ e $10 .^{\circ}$ andar do prédio do Hospital das Clínicas (Carvalho, 1980). O prédio da Escola foi oficialmente inaugurado no dia 31 de outubro de 1947, quando então o internato passou para esse prédio novo, onde funcionou até ser extinta a obrigatoriedade de residência dos alunos.

Dados da ABEn (1980) demonstram que, em 1956, vinte e duas escolas de enfermagem mantinham residência que funcionavam em prédios adaptados, o que dificultava as atividades curriculares, pois era recomendado que os quartos fossem individuais, permitindo a privacidade à estudante, pois este era considerado um lar para as mesmas.

Este acervo convida o visitante a adentrar um período histórico que marcou os primórdios da EEUSP, permitindo que o mesmo se sinta parte dessa história.

\section{CONCLUSÕES}

Todos os acervos mencionados encontram-se no Centro Histórico Cultural da Enfermagem Ibero Americana e na Biblioteca "Wanda de Aguiar Horta" da Escola de Enfermagem a USP.

- A reestruturação do Centro Histórico levou a um movimento de redescobrimento das obras que estavam armazenadas em um espaço esquecido, permitindo que elas ganhassem vida e visibilidade dentro do ensino e pesquisa da enfermagem.

- A catalogação, higienização e digitalização dos documentos, fotos e artigos jornalísticos permitem ampliar o 


\section{Cultura de los Cuidados}

acesso à história, abrindo espaço para novas discussões e interpretações dos acontecimentos históricos que marcaram a enfermagem brasileira e iberoamericana.

- O envolvimento de vários atores em diferentes níveis permitiu uma troca essencial de experiências, ampliando a vivência e o entendimento destes em relação à importância da história e sua preservação para a formação do futuro de uma profissão.

- A reinauguração do novo Centro Histórico, em um espaço acessível e melhor distribuído aumentou o número de visitas ao local, que hoje é parada obrigatória em atividades de algumas disciplinas de graduação e pósgraduação da Instituição, bem como nas atividades que buscam expor o que é e o que faz a enfermagem, como é o caso do evento "USP e as profissões", promovido pela Pró-Reitoria de Cultura e Extensão.

Este "novo" CHCEIA conseguiu alcançar seu objetivo, de não ser um museu estático e sem vida, mas de ser um local de reconstrução da identidade e da história de uma profissão, por muitas vezes, mistificada.

\section{REFERÊNCIAS}

- Associação Brasileira de Enfermagem. Diretrizes para a Enfermagem no Brasil: relatório final do levantamento de recursos e necessidades da Enfermagem no Brasil1956/158. Brasília, 1980.

- Barros, J. A. (2013). O campo da história: especialidades e abordagens. 9. a ed. Petrópolis, Rio de Janeiro: Vozes.

- Bellaguarda, M. L. R., Silveira, L. R., Mesquita, M. P. L., Ramos, F. R. S. (2011). Identidade da profissional enfermeira caracterizada numa revisão integrativa. Enferm. em Foco, 2(3), 180-3. Recuperado: http://biblioteca.cofen.gov.br/wpcontent/uploads/2016/01/Identidade-da-profissionalenfermeira-caracterizada-numa-revisao- integrativa.pdf.

- Bergamo, A. (2011). Reportagem, memória e história no jornalismo brasileiro. Mana, 17(2), 233-69. Recuperado:

http://www.scielo.br/pdf/mana/v17n2/a01v17n2.

- Campos, P. F. S., Porto, F., Oguisso, T., Freitas, G. F. (2008). Memória da saúde em São Paulo: Centro Histórico Cultural da Enfermagem Ibero-Americana. Cad. Hist. Ciênc., São Paulo, 4(1), 39-51. Recuperado: http://periodicos.ses.sp.bvs.br/pdf/chci/v4n1/a03v4n 1.pdf.

- Carvalho, A. C. (1976). Associação Brasileira de Enfermagem - 1926-1976, documentário. Brasília: ABEn.

- Carvalho, A. C. (1980). Escola de Enfermagem da Universidade de São Paulo: resumo histórico 1942-1980. São Paulo: Sangirard.

- Cianciarullo, T. I. (1992). Solenidade de inauguração do Centro Histórico de Enfermagem Ibero Americana. [DVD]. Brasil. São Paulo: Escola de Enfermagem da Universidade de São Paulo.

- Conselho Regional de Enfermagem. (2015). Terceira Idade - como assistir a saúde da faixa etária que será a maioria em poucos anos no Brasil? Enferm. em Rev., 13, 40-1. Recuperado: http://portal.corensp.gov.br/sites/default/files/revista coren sp dezem bro 2015.pdf.

- Freitas, G. F., Oguisso, T., Takashi, M. H., Silva TA., Bonini, B. B., Silva, E. C. (2016). Acervos do Centro Histórico Cultural da Enfermagem Ibero Americana, da Escola de Enfermagem da USP: do passado ao presente. In: V SIAHE, Simposio Iberoamericano de Historia de la Enfermería y III Foro I+E, Reunión Internacional de Investigación y Educación Superior en Enfermería. Granada, Espanha. La Enfermería como integradora de saberes, n. 25.

- Galvão, A. M. O. (2006). Oralidade e escrita: uma revisão. Cad. de Pesquisa, 36(128), 403-32. Recuperado: http://www.scielo.br/pdf/cp/v36n128/v36n128a07.pdf.

- Gastaldo, D. M., Meyer, D. E. (1989). A formação da enfermeira: ênfase na conduta em detrimento do conhecimento. Rev Bras Enferm, 42(1-4), pp. 7-13. Recuperado: $\quad$ http://dx.doi.org/10.1590/S003471671989000100002 .

- Luchesi, L. B., Mendes, I. A. C., Luis, M. A. V., Saeki, T. (2006). Redescobrindo o Centro de Memória da Escola de Enfermagem de Ribeirão Preto: relato de experiência. Esc. Anna Nery, 10(3), 565-71. Recuperado:

http://www.scielo.br/pdf/ean/v10n3/v10n3a29.pdf.

- Maia, T. A. (2012). Políticas culturais e patrimônio histórico: as ações do conselho federal de cultura (1967-1975). Rev. Memória em Rede, Pelotas, 2(7), 1-17. Recuperado:

https://periodicos.ufpel.edu.br/ojs2/index.php/Mem oria/article/view/9491/6270. 
- Mecone, M. C. (2014). O modelo militar no ensino de enfermagem: um olhar histórico soba perspectiva foucaultiana. (Tese de doutorado). Escola de Enfermagem da Universidade de São Paulo: São Paulo.

Recuperado: http://www.teses.usp.br/teses/disponiveis/7/7140/td e-07012015-103236/pt-br.php.

- Oguisso, T. (2000). Memória e História: Centro Histórico-Cultural da Enfermagem Ibero-Americana. Escola Anna Nery. Rev. Médicis, Rio de Janeiro, 4(3/3), 359-67.

- Oguisso, T., Freitas, G. F., Takashi, M. H. (2013). Edith de Magalhaes Fraenkel: o maior vulto da Enfermagem brasileira. Rev. Esc. Enferm. USP, 47(5), 1219-26, 2013.2 Recuperado: http://www.scielo.br/pdf/reeusp/v47n5/pt_00806234-reeusp-47-05-1219.pdf.

- Oguisso, T. (2016). Trajetória Profissional de Amália e Anayde Corrêa de Carvalho. In: Oguisso, T., Freitas, G. F. \& Siles, J. organizadores. Enfermagem: história, cultura dos cuidados e métodos (pp. 29-66). Rio de Janeiro: Águia Dourada.

- Padilha, M.I., Nelson, S., Borenstein, M.S. (2011). As biografias como um dos caminhos na construção da identidade do profissional da enfermagem. Hist. Cienc. Saúde-Manguinhos, 18(Suppl 1), 241-52. Recuperado: http://www.scielo.br/pdf/hcsm/v18s1/13.pdf.

- Porto, F., Campos, P. F. S., Oguisso, T. (2009). Cruz Vermelha Brasileira (Filial São Paulo) na Imprensa (1916-1930). Esc. Anna Nery Rev. Enferm., 13(3), 492-99. Recuperado: http://www.scielo.br/pdf/ean/v13n3/v13n3a06.pdf.

- Silva, T. A. (2015). Identidade e escolhas profissionais na perspectiva de graduandos de enfermagem. (dissertação de mestrado). Escola de Enfermagem da Universidade de São Paulo: São Paulo. Recuperado: http://www.teses.usp.br/teses/disponiveis/7/7140/td e-08012016-145526/pt-br.php.

- Secaf, V., Sanna, M. C. (2003). "Levantamento de Recursos e Necessidades de Enfermagem no Brasil" um documento da década de 50 do século XX. Rev. Bras. Enferm., 56(3), 315-7. Recuperado: http://www.scielo.br/pdf/reben/v56n3/a20v56n3.pdf. 